\title{
Antibody-induced modulation of TSH receptor post-translational processing
}

\author{
Takao Ando, Rauf Latif and Terry F Davies \\ Thyroid Research Unit, Mount Sinai School of Medicine, The James J Peters VA Medical Center, Box 1055, 1 Gustave L Levy Place, New York, \\ New York 10029, USA \\ (Correspondence should be addressed to T F Davies; Email: terry.davies@mssm.edu)
}

\begin{abstract}
The post-translational processing of the TSH receptor (TSHR) includes intra-molecular cleavage with the loss of a 50 amino acid ectodomain region and the formation of two subunits $(\alpha$ and $\beta$ ), followed by likely $\alpha$ subunit shedding. TSHR antibodies (TSHR-Abs), which are directed at the ectodomain, may influence thyroid function by stimulating or inhibiting TSHR signaling or may bind without any such influence (the neutral group of antibodies). When we examined the characteristics of a series of monoclonal TSHR-Abs, we found that many were able to inhibit
\end{abstract}

receptor cleavage and enhance TSHR expression. This was especially apparent with the neutral type of TSHR-Abs directed to the cleaved region of the ectodomain (aa 316-366). Indeed, such inhibition appeared to be epitope dependent with TSHR-Abs directed to regions after residues 335-354 showing no such activity. We propose that this aberrant process, whereby TSHR-Abs influence antigen processing, is a novel mechanism for the maintenance and exacerbation of autoimmune thyroid disease.

Journal of Endocrinology (2007) 195, 179-186

\section{Introduction}

The thyrotropin receptor (TSHR) is first expressed as a holoreceptor and then constitutively undergoes intramolecular cleavage (Misrahi et al. 1994, Tanaka et al. 1999, Latif et al. 2004). The complete or incomplete loss of the cleaved region (residues $\sim 316-366$ ) is followed by the formation of a two subunit structure (Misrahi et al. 1994, Tanaka et al. 1999); the extracellular $\alpha$ (or A) subunit and a $\beta$ (or B) subunit - made up of the remaining (sometimes variable length) ectodomain, the transmembrane loops, and the endodomain. Both subunits are stabilized by disulfide bonds and most likely additional contact points. Our earlier findings have shown that there is profound inter-molecular interaction between TSHRs resulting in dimerization and multimerization (Graves et al. 1996, Latif et al. 2001, 2002) and these observations have recently been confirmed (Urizar et al. 2005). We have also suggested that the dissociation of multimers into monomeric forms may be required for intramolecular cleavage (Latif et al. 2004). It has also been shown that after reduction of the disulfide bonds holding the subunits together, the TSHR may shed its $\alpha$ subunit (Couet et al. 1996, Latif et al. 2004; Fig. 1A). This fragment of shed $\alpha$ subunit has never been detected in the peripheral circulation, most likely because it accumulates in draining lymph nodes or is rapidly degraded. This spontaneous and irreversible posttranslational processing explains why $\beta$ subunits predominate 2.5- to 3-fold more than the $\alpha$ subunits (Loosfelt et al. 1992,
Misrahi et al. 1994). However, the percentage of surface receptors that are cleaved at any one time varies from a minority of uncleaved holoreceptors remaining on the thyroid cell surface to a substantial proportion (Misrahi et al. 1994). Furthermore in transfected mammalian non-thyroid cells expressing recombinant TSHRs, such constitutive cleavage is inefficient leading to a greater density of uncleaved holoreceptors on the cell surface than seen in thyroid cells (Misrahi et al. 1994, Rapoport et al. 1998). Deletion of the cleaved region in the TSHR ectodomain does not affect TSH binding to, nor activation of, the TSHR (Chazenbalk et al. 1999) and, therefore, its relationship to receptor structure and dimerization remains a point of interest.

The TSHR is the major autoantigen in autoimmune thyroid disease. Autoantibodies to the TSHR (TSHR-Abs) may influence thyroid function by stimulating the TSHR and promoting excessive thyroid growth, hormone production, and hormone secretion causing Graves' disease (GD; Rees Smith et al. 1988, Rapoport et al. 1998, Ando et al. 2005). TSHR-Abs may also block the action of TSH and induce hypothyroidism as seen in some patients with the atrophic form of Hashimoto's thyroiditis (Rees Smith et al. 1988, Ando et al. 2005).

In this study, we show that many TSHR-Abs inhibit TSHR post-translational cleavage. These data introduce a new concept by which TSHR antibodies regulate post-translational processing of their antigen. We hypothesize that antibody-mediated persistence of excess uncleaved TSHRs may result in an increased TSHR antigenic load. 
A

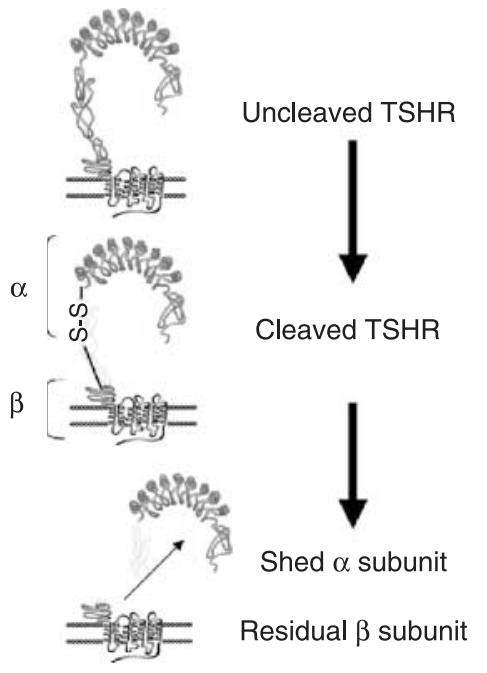

B

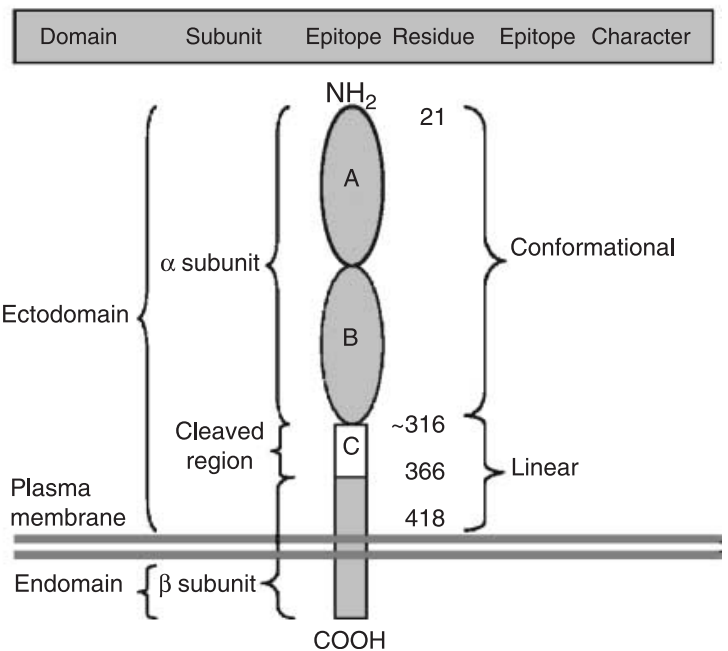

Figure 1 TSHR structure, post-translational processing, and epitope geography. (A) Three forms of the TSHR: the TSH holoreceptor undergoes cleavage and loses residues $\sim 316-366$. This results in the formation of a two subunit structure ( $\alpha$ and $\beta$ ) connected by disulfide bonds and is referred to as the cleaved TSHR. Upon reduction, the $\alpha$ subunit (making up much of the ectodomain) is shed from the cell surface and leaves the $\beta$ subunits on the membrane. This processing of the TSHR is constitutive and irreversible (adapted from Davies et al. 2002). (B) Schematic representation of the structure of the TSHR and the epitopes recognized by TSHRmAbs. A 50 AA region removed by TSHR cleavage (cleaved region) is shown in white. The capital letters (A-C) indicate the three major epitopes recognized in a hamster model of GD (Ando et al. 2004a). Epitopes shown as oval indicate conformational recognition, and squares indicate linear recognition regions. Note that the ectodomain consists of more than just the TSHR $\alpha$ subunit.

\section{Materials and Methods}

\section{Cells and TSHR-mAbs}

CHO-TSHR cells (Perret et al. 1990) stably expressing the human TSHR (kindly provided by Dr G Vassart, Universite Libre de Bruxelles and Service de Genetique Medicale, Brussels, Belgium) were maintained as previously described (Ando et al. 2002). FRTL-5 cells, a rat thyroid cell line (Ambesi-Impiombato et al. 1980), were maintained as previously described (Davies et al. 1987). Monoclonal TSHR-Abs Mount Sinai-1 (MS-1), 9F4, thyroid antibody (TAb)-8, 7G10, TAb-6, and TAb-16 are Armenian hamster $\mathrm{IgG}_{2} \mathrm{mAbs}$ (Ando et al. 2002, 2004a). Concentrations of hamster $\mathrm{mAb}$ used were saturating unless otherwise indicated. Monoclonal TSHR-Abs M1 and M4, used in our cleavage assay, were mouse $\operatorname{IgG}_{1}$ (Oda et al. 1998, 2000) kindly supplied by Dr B Rees Smith (RSR Limited, Cardiff, UK). 2C11 was a mouse IgG 1 TSHR-mAb (Shepherd et al. 1999) purchased from Serotec (Raleigh, NC, USA). The biotinylation of mAbs was described previously (Latif et al. 2004).

\section{TSHR peptide ELISA}

Hamster serum binding to TSHR peptides was performed as previously described (Ando et al. 2004a). The human TSHR peptides (Morris et al. 1993) used were residues 307-326, 322-341, 337-356, 352-371, 367-386, and 382-401 (kindly provided by Dr J Morris, Mayo Medical School, Rochester, MN, USA). For examination of human sera binding to peptides, we incubated serum (1:10) with peptide-coated wells for $2 \mathrm{~h}$. After washing, biotinylated TAb-6 $(500 \mathrm{ng} / \mathrm{ml})$ or TAb-16 (200 ng/ml) was used to study binding inhibition. The concentrations of these labeled mAbs were determined as optical density $(\mathrm{OD}) \sim 1$. The percentage of inhibition was expressed by the percentage of reduction of OD by sera based on that with biotinylated $\mathrm{mAb}$ alone. Positive was defined as an inhibition $>2$ s.D. from the mean of control sera.

\section{TSHR expression and cleavage determined by flow cytometry}

TSHR cleavage has been studied mainly by chemical crosslinking of TSHRs and detection with radioiodine-labeled TSH (Rapoport et al. 1998). However, we have recently shown that this method is not suitable for studying the dynamic changes that occur with TSHR cleavage or expression (Latif et al. 2004). Therefore, to study the dynamic influence of TSHR-Abs on TSHR cleavage, we used a flow cytometric-based assay for quantitating TSHR cleavage (Ando et al. 2002, Latif et al. 2004). In brief, after incubating cells with a TSHR-mAb for $24 \mathrm{~h}$, or as otherwise indicated, we aliquoted and stained CHO-TSHR cells with TSHR-mAb-M1 (binding to residues 381-385 in the $\beta$ subunit) and M4 (binding to residues 322-341 in the cleaved region of the TSHR). Anti-mouse $\operatorname{IgG}_{1}$ conjugated with FITC 
(Roche Applied Sciences; 1:200) was used as the secondary Ab. The mean fluorescent intensity was then determined by a FACS calibur instrument (FACS shared facility at Mount Sinai School of Medicine, BD Bioscience Pharmingen, San Diego, CA, USA) as a measure of $\mathrm{mAb}$ binding. We excluded dead cells by staining with propidium iodide $(5 \mu \mathrm{g} / \mathrm{ml})$. In some experiments, after similarly incubating cells, we stained cells with biotinylated TSHR-mAb-9F4 (binding to epitope A in the $\alpha$ subunit; $5 \mu \mathrm{g} / \mathrm{ml}$ ) on ice for $1 \mathrm{~h}$ followed by avidin-PE (BD Bioscience Pharmingen). The relative b9F4 binding was expressed based on b9F4 binding to control $\mathrm{CHO}$ cells. When we studied cleavage in FRTL-5 thyroid cells (Ambesi-Impiombato et al. 1980), we withdrew TSH from the culture media for 5 days before. We also used TSHR-mAB-TAb-16 instead of M4, and probed with anti-hamster $\kappa$ chain conjugated with biotin (BD Bioscience Pharmingen), due to stronger binding of TAb-16. Bovine TSH was from Sigma-Aldrich.

\section{Membrane preparation and western blotting}

In each experiment, three plates (100 $\mathrm{mm}$ dishes) of CHOTSHR cells were treated with $2 \mu \mathrm{g} / \mathrm{ml}$ TAb- 8 for $24 \mathrm{~h}$. The cells were washed and were subjected to membrane preparation using digitonin as described previously (Latif et al. 2001). Equal amounts of the protein from treated and untreated $\mathrm{CHO}-$ TSHR cell preparations were exposed to $5 \times$ sample buffer and resolved on $12 \%$ SDS-PAGE. The blot was probed with an N-terminus-specific TSHR murine monoclonal antibody (A10) for the presence of uncleaved receptor. Antibody to $\beta$-actin at 1:1000 was used to show equal loading of the gel.

\section{Data analysis}

Prism 4 (Graphpad software Inc., San Diego, CA, USA) was used to analyze the data. Student's $t$-test or one-way ANOVA was used for statistical analysis. A value of $P<0.05$ was considered significant.

\section{Results}

Antibodies to the cleaved region of the TSHR in a hamster model of GD

When we examined 18 sera from hamsters with GD, including those animals included in a previous study (Ando et al. 2004a), we found that the majority of sera $(14 / 18)$ recognized linear epitopes on synthetic TSHR peptides corresponding to the cleaved region (residues 316-366; Fig. 2). This emphasized our previous finding that the major linear epitope in our model was in this region (designated epitope C; Fig. 1; Ando et al. 2004a).

\section{Regulation of TSHR cleavage by TSHR-mAbs}

Since we previously showed that under appropriate conditions TSH positively influenced TSHR cleavage (Latif et al. 2004), we

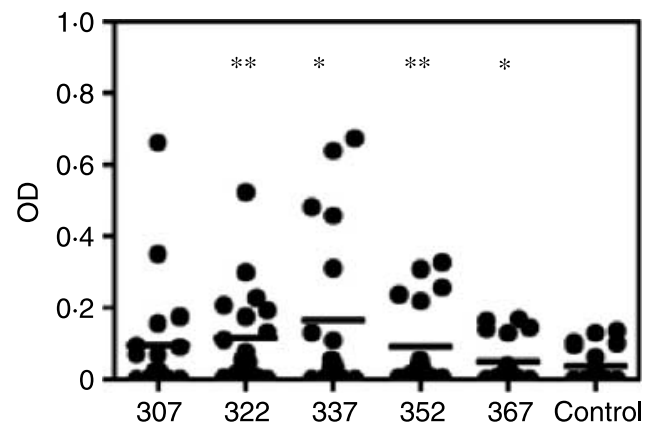

Figure 2 Recognition of the TSHR cleaved region by sera from a hamster model of Graves' disease. TSHR-Abs to the cleaved region in sera from a hamster model of GD as determined by TSHR peptide ELISAs. The numbers shown below each column indicate the initial AA of each synthetic peptide as described in the Materials and Methods section. Immunoreactivity (OD) was compared with peptide 382 and an irrelevant control $\mathrm{mAb}$ (data are mean of duplicate measurements). ${ }^{*} P<0 \cdot 05$ and ${ }^{* *} P<0 \cdot 01$.

hypothesized that TSHR-mAbs may also influence TSHR cleavage. In order to determine the influence of TSHR-mAbs on TSHR cleavage, we incubated CHO cells overexpressing TSHRs (CHO-TSHR; Perret et al. 1990) with hamster-derived TSHR-mAbs of known epitope specificity (Ando et al. 2004a; Table 1). In order to assess changes in TSHR cleavage, we used a FACS-based system previously described by this laboratory (Ando et al. 2002, Latif et al. 2004). We measured the uncleaved receptor by the binding of a well-characterized murine $\mathrm{mAb}$ to the unique cleaved region (M4) and the 'assumed' total (cleaved and uncleaved) TSH receptor population by a murine $\mathrm{Ab}$ to the $\beta$ subunit (M1). The M1 antibody detected any change in total TSHR expression, such as down-regulation, which would also influence M4 binding and, therefore, served as control. We expressed TSHR cleavage as a relative ratio of M4 to M1 binding. Any reduction in this ratio was taken as an indication of enhanced cleavage and vice versa (Ando et al. 2002, Latif et al. 2004). As we previously showed, TSH decreased this ratio in a dose-dependent manner, which indicated mild enhancement of receptor cleavage (Fig. 3, inset). We next studied the influence of TSHR-mAbs to epitope A (on the $\alpha$ subunit) on TSHR cleavage (Fig. 3). Both TSHR-stimulating mAb (MS-1) and blocking $\mathrm{mAb}$ (9F4) inhibited rather than enhanced TSHR cleavage to a modest degree when present in high concentrations. We then examined the influence of a blocking TSHR-mAb known to bind to epitope $\mathrm{B}(\mathrm{TAb}-8)$ and a neutral TSHR-mAb to epitope C (7G10). Both TAb-8 and 7G10 inhibited TSHR cleavage to a marked degree (Fig. 3). TAb-6 had no influence on cleavage. Therefore, in contrast to TSH, some TSHR-mAbs increased the cleavage ratio in a dose-dependent manner, indicating inhibition of constitutive cleavage.

\section{Time dependency of TSHR-Ab effects}

We also studied the time dependency of this antibody inhibition of cleavage. TSH $(100 \mu \mathrm{U} / \mathrm{ml})$ induced such 
Table 1 Summary of thyrotropin receptor (TSHR)-mAbs used in this study and their influence on the TSHR

\begin{tabular}{|c|c|c|c|c|c|}
\hline & Species & Function $^{\mathrm{a}}$ & Epitope $^{b}$ & $\alpha$ subunit $^{\mathrm{C}}$ & Cleavage $^{d}$ \\
\hline MS-1 & Hamster & Stimulating & A, conformational ${ }^{\mathrm{e}}$ & Increase $^{f}$ & Inhibitory \\
\hline TAb-8 & Hamster & Blocking & $\mathrm{B}$, conformational $\mathrm{e}^{\mathrm{e}}$ & Increase & Inhibitory \\
\hline TAb-16 & Hamster & Neutral & C, residues $322-341$ & Increase & Inhibitory \\
\hline 7G10 & Hamster & Neutral & C, residues 335-354 & Increase & Inhibitory \\
\hline TAb-6 & Hamster & Neutral & C, residues 335-354 & No change & No change \\
\hline M1 & Mouse & Blocking & Residues 381-385 & No change & No change \\
\hline
\end{tabular}

aThe functions of all TSHR-mAbs were studied in CHO-TSHR cells. Stimulating mAb increased the intracellular cAMP production via TSHR. Blocking mAbs inhibited labeled TSH binding to the TSHR without increasing the intracellular cAMP. Neutral mAb had neither activity.

${ }^{b}$ Epitopes A-C correspond to those in Fig. $1 b$.

cInfluence on $\alpha$ subunit content of the TSHR.

dinfluence on TSHR cleavage.

${ }^{\mathrm{e}}$ Conformational epitopes A and B are localized within the first 316 amino acids (Ando et al. 2002, 2004a), but distinct from each other (Ando et al. $2004 a$, b). fDetermined using TAb-8 labeled with fluorescent dye, relative TAb-8 binding increased over M1 binding.

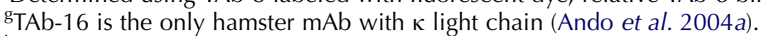

${ }^{\mathrm{h}}$ Determined by change in b9F4 binding (for details see text).

changes within $6 \mathrm{~h}$ (relative M4/M1; 0.825 $\pm 0 \cdot 003, P<0 \cdot 05$ vs $0 \mathrm{~h}$ ). Blocking mAbs (9F4 and TAb-8; at $2 \mu \mathrm{g} / \mathrm{ml}$ ) inhibited cleavage within $3 \mathrm{~h}(1 \cdot 395 \pm 0 \cdot 042, P<0 \cdot 0005$ for TAb-8 and $1.229 \pm 0.037 P<0.005$ for $9 F 4)$ and reached a plateau at $24 \mathrm{~h}$ and continued to influence cleavage for at least $72 \mathrm{~h}$ (data not shown). However, the increase in the M4 to M1 ratio obtained in the FACS cleavage assay was not able to indicate whether inhibition of cleavage was complete or incomplete and could not assess constitutive activity.

\section{Epitope dependency of cleavage inhibition}

All but one of the hamster TSHR-mAbs used in this study; stimulating, blocking, and neutral, inhibited TSHR cleavage (Table 1). This indicated that inhibition of cleavage was not dependent on signal transduction at the TSHR. Since these hamster mAbs bound proximal to residue 354 (Table 1), we obtained and examined two mouse mAbs binding distal to residue 354 (Fig. 4). These two mouse mAbs (2C11 and M1) which bound to linear residues 354-359 and 381-384 respectively, did not inhibit cleavage as evidenced by a lack of increase in the binding of an $\alpha$ subunit probe (9F4). Thus, inhibition of TSHR cleavage depended on the epitope recognized within the TSHR ectodomain proximal to residue 354. However, two of the neutral mAbs (TAb-6 and 7G10) recognizing residues 335-354 had different CDR3 sequences (not shown) but only one of them (7G10) inhibited TSHR cleavage. This suggested that residues 335-354 represented the border between residues for cleavage- and non-inhibitory Abs.

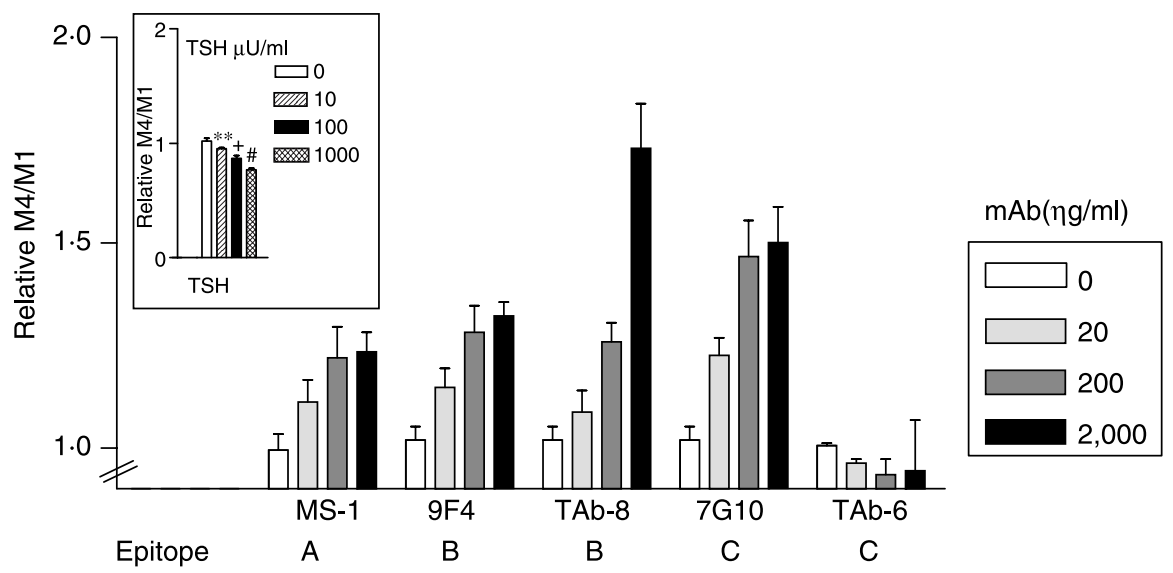

Figure 3 Inhibition of TSHR cleavage by TSHR-mAbs. Cleavage was measured using the flow cytometric cleavage assay as described in Materials and Methods. Data on the regulation of TSHR cleavage are shown after incubating cells with TSH (inset) or increasing concentrations $(20-2000 \mathrm{ng} / \mathrm{ml}$ ) of TSHR-mAbs (mean \pm S.E.M. of more than three independent experiments). ${ }^{* *} P<0 \cdot 01,{ }^{+} P<0 \cdot 001$, and ${ }^{\#} P<0 \cdot 0005$. 


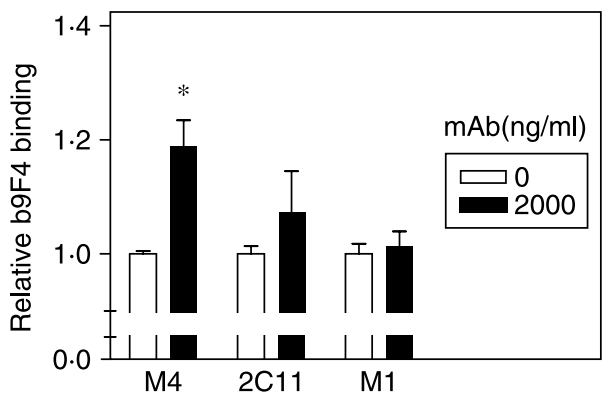

Figure 4 Epitope dependency of cleavage inhibition. TSHR expression assessed by biotinylated TSHR-mAb-9F4 after incubating cells with two mouse TSHR-mAbs (2C11 and M1) binding distal to residue 354. M4, binding to residues 322-341, enhanced 9F4 binding and served as a positive control, but 2C11 and $\mathrm{M} 1 \mathrm{mAbs}$ failed to show any enhancement (data expressed as mean \pm s.E.M. of duplicate measurements from three independent experiments). ${ }^{*} P<0 \cdot 005$.

\section{Effects of TSHR-mAbs on recombinant TSHR expression}

The $\alpha$ subunit is the site(s) which contains the epitope for many TSHR-Abs and also contains a region which appears to suppress the constitutive activity of the TSHR (Zhang et al. 2000, Vlaeminck-Guillem et al. 2002). Our results suggested that TSHR-Abs directed at either the $\alpha$ subunit or the cleaved region influenced the variety of TSHR forms present on the cell surface. However, the increase in the M4 to M1 ratio obtained in the FACS cleavage assay was not able to indicate whether inhibition of cleavage was complete or incomplete. Incomplete cleavage has been evidenced as a variation in $\beta$ subunit size and sequence shown in transfected cells (de Bernard et al. 1999, Tanaka et al. 1999, Oda et al. 2000). Since we found that the M1 antibody increased the $\alpha$ subunit content of the cell by studying the cell surface binding of a TSHR-mAb probe to epitope A (biotinylated 9F4; Fig. 4), we decided to examine this approach in more detail (Ando et al. 2004a). Using this probe to epitope A, we examined the influence of a blocking TSHR-mAb to epitope
B and three neutral TSHR-mAbs to epitope C, described earlier, and also known a) not to interfere with the epitope $\mathrm{A}$ probe binding (Ando et al. 2004a,b) and b) not able to alter probe-binding affinity (as evidenced by consistent $\mathrm{IC}_{50}$; data not shown). Three of these mAbs also increased the probe binding in a dose-dependent manner (mean increase $~ 50 \%$; Fig. 5), although one neutral $\mathrm{mAb}$ (TAb-6) which did not inhibit cleavage failed to demonstrate this effect. This increased binding of the probe observed with TAb-8treated cells was not associated with any major affinity changes in the cell surface receptors (Fig. 5B). These results suggested that only cleavage-inhibiting mAbs increased the amount of TSHR $\alpha$ subunit. A linear correlation between the increase in $\alpha$ subunit content and the degree of cleavage inhibition (Fig. 6; $r=0.988, \quad P<0 \cdot 0001$ ) was also compatible with inhibition of TSHR cleavage leading to increased intact TSHR expression. We tried to examine whether this change in surface receptors was detectable by immunoblotting. We treated CHO-TSHR cells with $2 \mu \mathrm{g} / \mathrm{ml}$ TSHR-mAb for $24 \mathrm{~h}$ and measured the full-length receptor using an amino terminus-specific antibody. This showed only minimal change in TSHR-mAb binding to surface TSHRs (Fig. 7). We concluded that, most likely, the incomplete degree of TSHR cleavage in these transfected cells made it difficult to detect changes in TSHR with the TSHR-Ab probes utilized in the immunoblot (Fig. 7).

\section{Regulation of TSHR cleavage in a thyroid cell line}

In order to examine whether the data obtained in transfected cells were physiologically relevant, we studied regulation of cleavage on rat thyroid cells (FRTL-5) which express low numbers of receptor (Ambesi-Impiombato et al. 1980). We first examined the state of the TSHRs expressed. Total TSHR expression was detectable by a TSHR-mAb to the $\beta$ subunit (M1; Table 2). We used two antibodies to the cleaved region (M4 and Tab-16) but could not observe antibody binding,
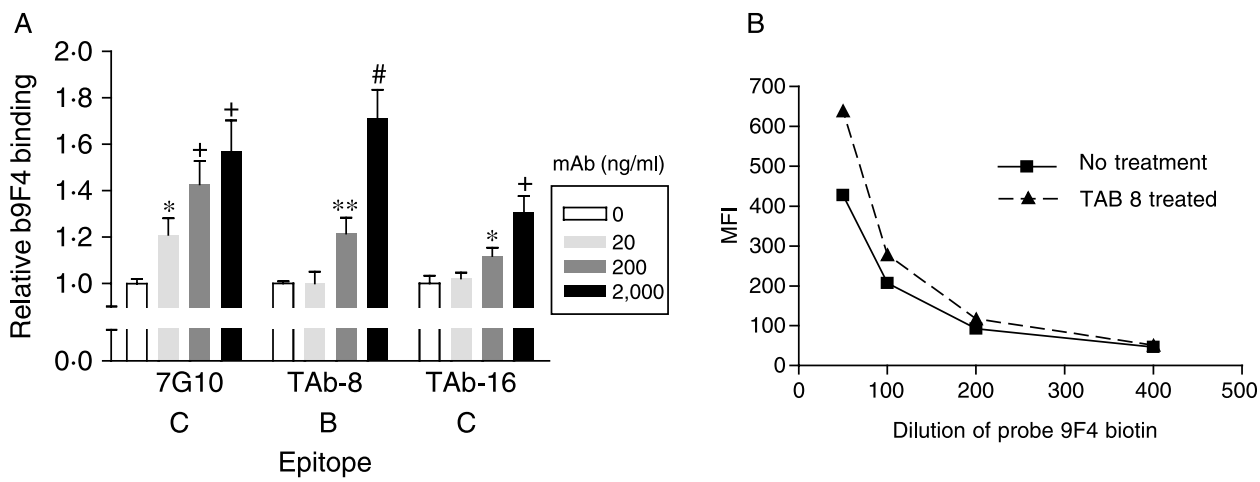

Figure 5 Dose dependency of enhanced TSHR-mAb-induced TSHR expression. (A) TSHR expression of biotinylated TSHR-mAb-9F4 is shown after incubating CHO-TSHR cells with the indicated mAb concentration (data expressed as mean \pm S.E.M. of duplicate measurements in four independent experiments). ${ }^{*} P<0 \cdot 05,{ }^{* *} P<0 \cdot 01,{ }^{+} P<0 \cdot 001$, and ${ }^{\#} P<0 \cdot 0005$. (B) Maximum fluorescence intensity of $9 \mathrm{~F} 4$ binding before and after exposure of CHO-TSHR cells to mAb TAb-8. 


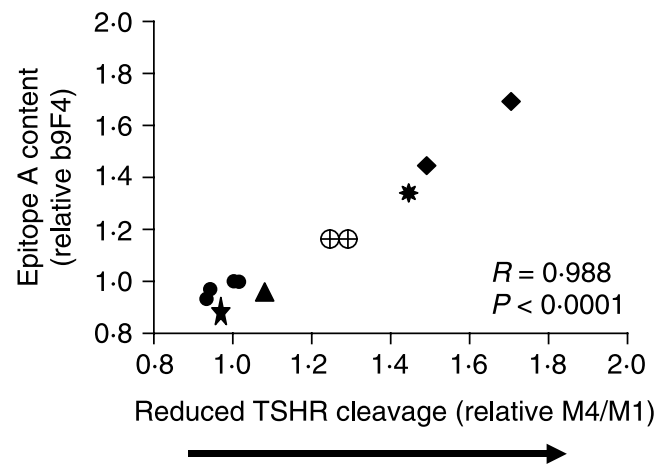

Figure 6 Correlation between TSHR expression and TSHR cleavage. Changes in binding of TSHR-Ab to epitope A after antibody exposure compared with the changes in TSHR cleavage induced by the same antibody. Data from 11 experiments are shown from six different $\mathrm{mAbs}$, each antibody represented by a different symbol.

demonstrating that constitutive cleavage in the cell line was almost complete after culture with TSH (Table 2). After exposure of FRTL-5 cells to TSHR-mAbs (9F4 and TAb-8), we were then able to detect cleaved region antibody binding compatible with cleavage inhibition (Table 2).

\section{Discussion}

TSHR-Abs have been considered as pathogenic in autoimmune thyroid disease because they activate or inactivate TSHR signaling (Rees Smith et al. 1988, Rapoport et al. 1998, Ando et al. 2005) although the clinical significance of neutral TSHRAbs, which have no such actions, has been uncertain (Ando et al. 2005). We observed that almost all monoclonal TSHR-Abs regulated TSHR post-translational changes on the cell surface including the neutral variety by effectively inhibiting cleavage of the TSHR. This phenomenon was epitope dependent and restricted to $\mathrm{mAbs}$ binding to amino acids 1-354. Such regulated post-translational processing by TSHR-mAbs was also observed in a rat thyroid cell line implying a functional significance to this post-translational influence.

There have been extensive biochemical investigations of TSHR intra-molecular cleavage (Rapoport et al. 1998, Tanaka et al. 1998, 2000, de Bernard et al. 1999, Siffroi-Fernandez et al. 2001) but the physiologic role, if any, for such processing has not been resolved. We have shown that TSH enhanced TSHR cleavage (Ando et al. 2002, Latif et al. 2004) as well as subsequent shedding of the $\alpha$ subunit in vitro (Couet et al. 1996, Latif et al. 2004). This regulation was not secondary to accumulation of intracellular cAMP (Couet et al. 1996, Latif et al. 2004). We recently found that TSH was not able to enhance cleavage of the TSHR ectodomain tethered with a short lipid tail (our unpublished data), excluding TSH as a cleaving enzyme. In the present study, we examined the influence of TSHR-Abs on TSHR cleavage using an mAb to epitope A (conformational epitope on the $\alpha$ subunit). Since epitope $A$ is present in both the uncleaved and cleaved TSHRs, our data indicated that cell surface expression was increased when TSHR-Abs inhibited TSHR cleavage. Previous evidence using a truncated TSHR, mimicking residual $\beta$ subunits, showed that truncated receptors had faster internalization and thus a shortened functional half-life (Quellari et al. 2003). Therefore, we concluded that TSH and TSHR-Abs had an opposite influence on this process and also that the constitutive and irreversible TSHR post-translational cleavage and shedding, involved TSHR degradation.

We have previously shown constitutive TSHR multimerization in vivo (Graves et al. 1996) and in vitro (Latif et al. 2001, 2002) and also that TSHR cleavage appeared to follow only monomeric, but not multimeric TSHR activation (Latif et al.
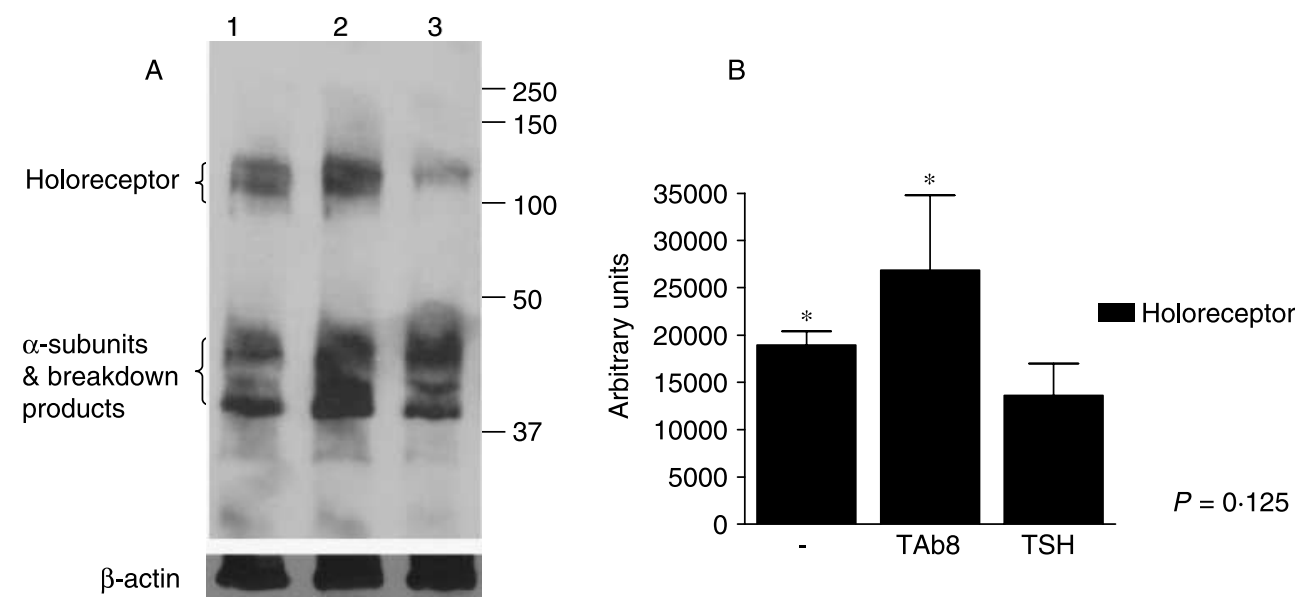

Figure 7 TSHR expression by immunoblot. Membranes prepared from TSH- and antibody-treated cells were resolved on $10 \%$ SDS-PAGE and blotted on to PVDF. The membrane was probed with an amino terminal TSHR-mAb (A10; Morgenthaler et al. 1997) at 1:5000 dilution. (A) Lane 1, untreated cells; lane 2, treated with TAb-8 antibody $(2 \mu \mathrm{g} / \mathrm{ml})$ for $24 \mathrm{~h}$; and lane 3 , treated with TSH $(1000 \mu \mathrm{U} / \mathrm{ml})$ for $24 \mathrm{~h} . * P<0 \cdot 01$. (B) Densitometric representation of the TSH holoreceptor bands indicated in (A). 
Table 2 Influence of blocking thyrotropin receptor (TSHR)-mAbs on TSHR expression in rat thyroid cells

MFI post-treatment
MAb

M1 probe

9F4

$\beta$ subunit

TAb-8

Cleaved region
MFI pre-treatment

$69 \cdot 48 \pm 2 \cdot 61$

$13 \cdot 32 \pm 0 \cdot 53$
$12 \mathrm{~h}$

$79 \cdot 30 \pm 2 \cdot 12$

$88 \cdot 60 \pm 3 \cdot 01$

$38 \cdot 24 \pm 0 \cdot 45$

$47.79 \pm 1.52$
$24 \mathrm{~h}$

$* 84 \cdot 22 \pm 3 \cdot 33^{*}$

${ }^{\ddagger} 85 \cdot 10 \pm 1 \cdot 67^{\ddagger}$

${ }^{+} 32 \cdot 80 \pm 2 \cdot 74^{\dagger}$

${ }^{\ddagger} 46 \cdot 27 \pm 1 \cdot 00^{\ddagger}$

The amount of the $\beta$ subunit and the cleaved region of the TSHR as determined by binding of M1 (binding to residue 381-385) and TAb-16 (residues 322-341) before and after incubating cells with the indicated blocking TSHR-mAb (at $20 \mu \mathrm{g} / \mathrm{ml})$ in the post-treatment columns. Note the increase in the cleaved region binding on treatment with TSHR-mAbs 9F4 and TAb-8. Data are expressed as maximum fluorescence intensity (MFI). ${ }^{*},{ }^{\dagger}$, and $^{\ddagger}$ indicate $P<0 \cdot 05, P<0 \cdot 01$, and $P<0 \cdot 001$ respectively, against pre-treatment.

2004). Our thyroid-stimulating monoclonal Ab (MS-1), which inhibited TSHR cleavage, induced a slowing of TSHR mobility suggesting the induction of TSHR dimers/multimers (Latif et al. 2004). Therefore, we propose that cleavage-inhibiting TSHRAbs stabilize the TSHR ectodomain by maintaining dimeric or multimeric TSHR forms due to their IgG bivalency. The mechanism by which multimerization may inhibit intramolecular cleavage of the TSHR is unknown. However, our data suggest that a structural inhibition of the cleavage enzyme(s) is the most likely. Evidence for this conclusion comes from the fact that the TSHR-Ab-induced inhibition of cleavage was epitope dependent. The detailed molecular explanation for such activity will need to await the identification and structure of the cleavage enzyme(s) involved in this phenomenon. However, it is likely that intact TSHR bound to a TSHR-Ab with cleavage-inhibiting activity is more resistant to degradation. Therefore, such TSHRs would have a higher chance of a subsequent interaction with additional TSHR-Abs with different epitope(s). We hypothesize that this action of multiple TSHR-Ab binding may have consequences in vivo. Such interactions may lengthen and sustain TSHR autoantigen expression, which would increase the autoantigenic load on the cell surface. Hence, inhibition of TSHR cleavage may play a role in maintaining and/or exacerbating GD.

In summary, we showed that TSHR-Abs binding to the ectodomain (the first $\sim 341$ amino acids), irrespective of their function, inhibited TSHR cleavage and likely increased the antigenic load of uncleaved TSHR. This concept of antibody-mediated regulation of the post-translational processing of a major autoantigen is novel and may be a more generalized mechanism involved in the maintenance and exacerbation of autoimmune disease.

\section{Acknowledgment}

This study was supported in part by NIH grants DK069713, DK052464, the VA Merit Award program and the David Owen Segal Endowment. The authors declare that there is no conflict of interest that would prejudice the impartiality of this scientific work.

\section{References}

Ambesi-Impiombato FS, Parks LA \& Coon HG 1980 Culture of hormonedependent functional epithelial cells from rat thyroids. PNAS 77 3455-3459. Ando T, Latif R, Pritsker A, Moran T, Nagayama Y \& Davies TF 2002 A monoclonal thyroid-stimulating antibody. Journal of Clinical Investigation 110 1667-1674.

Ando T, Latif R, Daniel S, Eguchi K \& Davies TF 2004a Dissecting linear and conformational epitopes on the native thyrotropin receptor. Endocrinology 145 5185-5193.

Ando T, Latif R \& Davies TF $2004 b$ Concentration-dependent regulation of thyrotropin receptor function by thyroid-stimulating antibody. Journal of Clinical Investigation 113 1589-1595.

Ando T, Latif R \& Davies TF 2005 Thyrotropin receptor antibodies: new insights into their actions and clinical relevance. Best Practice and Research. Clinical Endocrinology and Metabolism 19 33-52.

de Bernard S, Misrahi M, Huet JC, Beau I, Desroches A, Loosfelt H, Pichon C, Pernollet JC \& Milgrom E 1999 Sequential cleavage and excision of a segment of the thyrotropin receptor ectodomain. Journal of Biological Chemistry 274 101-107.

Chazenbalk GD, Tanaka K, McLachlan SM \& Rapoport B 1999 On the functional importance of thyrotropin receptor intramolecular cleavage. Endocrinology 140 4516-4520.

Couet J, Sar S, Jolivet A, Hai MT, Milgrom E \& Misrahi M 1996 Shedding of human thyrotropin receptor ectodomain. Involvement of a matrix metalloprotease. Journal of Biological Chemistry 271 4545-4552.

Davies TF, Yang C \& Platzer M 1987 Cloning the Fisher rat thyroid cell line (FRTL-5): variability in clonal growth and $3^{\prime} 5^{\prime}$-cyclic adenosine monophosphate response to thyrotropin. Endocrinology 121 78-83.

Davies TF, Marians R \& Latif R 2002 The TSH receptor reveals itself. Journal of Clinical Investigation 110 161-164.

Graves PN, Vlase H, Bobovnikova Y \& Davies TF 1996 Multimeric complex formation by the thyrotropin receptor in solubilized thyroid membranes. Endocrinology 137 3915-3920.

Latif R, Graves P \& Davies TF 2001 Oligomerization of the human thyrotropin receptor: fluorescent protein- tagged hTSHR reveals posttranslational complexes. Journal of Biological Chemistry 276 45217-45224.

Latif R, Graves P \& Davies TF 2002 Ligand-dependent inhibition of oligomerization at the human thyrotropin receptor. Journal of Biological Chemistry 277 45059-45067.

Latif R, Ando T \& Davies TF 2004 Monomerization as a pre-requisite for intramolcular cleavage and shedding of the thyrotropin receptor. Endocrinology 145 5580-5588. 
Loosfelt H, Pichon C, Jolivet A, Misrahi M, Caillou B, Jamous M, Vannier B \& Milgrom E 1992 Two-subunit structure of the human thyrotropin receptor. PNAS 89 3765-3769.

Misrahi M, Ghinea N, Sar S, Saunier B, Jolivet A, Loosfelt H, Cerutti M, Devauchelle G \& Milgrom E 1994 Processing of the precursors of the human thyroid-stimulating hormone receptor in various eukaryotic cells (human thyrocytes, transfected L cells and baculovirus-infected insect cells). European Journal of Biochemistry 222 711-719

Morgenthaler NG, Kim MR, Gardas A, Vlase H, Aust G, Gupta M, McGregor AM \& Banga JP 1997 Characterisation of the antibody response to the extracellular region of recombinant thyrotropin receptor. Autoimmunity 26 75-84.

Morris JC, Bergert ER \& McCormick DJ 1993 Structure-function studies of the human thyrotropin receptor. Inhibition of binding of labeled thyrotropin (TSH) by synthetic human TSH receptor peptides. Journal of Biological Chemistry 268 10900-10905.

Oda Y, Sanders J, Roberts S, Maruyama M, Kato R, Perez M, Petersen VB, Wedlock N, Furmaniak J \& Rees Smith B 1998 Binding characteristics of antibodies to the TSH receptor. Journal of Molecular Endocrinology 20 233-244.

Oda Y, Sanders J, Evans M, Kiddie A, Munkley A, James C, Richards T, Wills J, Furmaniak J \& Smith BR 2000 Epitope analysis of the human thyrotropin (TSH) receptor using monoclonal antibodies. Thyroid 10 1051-1059.

Perret J, Ludgate M, Libert F, Gerard C, Dumont JE, Vassart G \& Parmentier M 1990 Stable expression of the human TSH receptor in CHO cells and characterization of differentially expressing clones. Biochemical and Biophysical Research Communications 171 1044-1050.

Quellari M, Desroches A, Beau I, Beaudeux E \& Misrahi M 2003 Role of cleavage and shedding in human thyrotropin receptor function and trafficking. European Journal of Biochemistry 270 3486-3497.

Rapoport B, Chazenbalk GD, Jaume JC \& McLachlan SM 1998 The thyrotropin (TSH) receptor: interaction with TSH and autoantibodies. Endocrine Reviews 19 673-716.

Rees Smith B, McLachlan SM \& Furmaniak J 1988 Autoantibodies to the thyrotropin receptor. Endocrine Reviews 9 106-121.

Shepherd PS, Da Costa CR, Cridland JC, Glimore KS \& Johnstone AP 1999 Identification of an important thyrotropin binding sites on the human thyrotropin receptor using monoclonal antibodies. Molecular and Cellular Endocrinology 149 197-206.
Siffroi-Fernandez S, Costagliola S, Paumel S, Giraud A, Banga JP \& Franc JL 2001 Role of complex asparagine-linked oligosaccharides in the expression of a functional thyrotropin receptor. Biochemical Journal 354 331-336.

Tanaka K, Chazenbalk GD, McLachlan SM \& Rapoport B 1998 Thyrotropin receptor cleavage at site 1 does not involve a specific amino acid motif but instead depends on the presence of the unique, 50 amino acid insertion. Journal of Biological Chemistry 273 1959-1963.

Tanaka K, Chazenbalk GD, McLachlan SM \& Rapoport B 1999 Subunit structure of thyrotropin receptors expressed on the cell surface. Journal of Biological Chemistry 274 33979-33984.

Tanaka K, Chazenbalk GD, McLachlan SM \& Rapoport B 2000 Evidence that cleavage of the thyrotropin receptor involves a 'molecular ruler' mechanism: deletion of amino acid residues 305-320 causes a spatial shift in cleavage site 1 independent of amino acid motif. Endocrinology 141 3573-3577.

Urizar E, Montanelli L, Loy T, Bonomi M, Swillens S, Gales C, Bouvier M, Smits G, Vassart G \& Costagliola S 2005 Glycoprotein hormone receptors: link between receptor homodimerization and negative cooperativity. EMBO Journal 24 1954-1964.

Vlaeminck-Guillem V, Ho SC, Rodien P, Vassart G \& Costagliola S 2002 Activation of the cAMP pathway by the TSH receptor involves switching of the ectodomain from a tethered inverse agonist to an agonist. Molecular Endocrinology 16 736-746.

Zhang M, Tong KP, Fremont V, Chen J, Narayan P, Puett D, Weintraub BD \& Szkudlinski MW 2000 The extracellular domain suppresses constitutive activity of the transmembrane domain of the human TSH receptor: implications for hormone-receptor interaction and antagonist design. Endocrinology 141 3514-3517.

Received in final form 23 July 2007

Accepted 9 August 2007

Made available online as an Accepted Preprint 10 August 2007 